\title{
The Effects of Emotional Awareness on the Psychological Well-Being of Adolescents: Cognitive Emotion Regulation Strategies as Mediators
}

Taehee Kwak ${ }^{1}$, JungHa Lim $^{2}$

M. Sc., Department of Human Ecology, Graduate School of Korea University, Seoul, Korea ${ }^{1}$

Professor, Department of Home Economics Education, Korea University, Seoul, Korea ${ }^{2}$

청소년의 정서인식 능력이 심리적 안녕감에 미치는 영향:

인지적 정서조절 전략의 매개효과

곽태희 ${ }^{1}$, 임정하 ${ }^{2}$

고려대학교 대학원 생활과학과 석사졸업 ${ }^{1}$, 고려대학교 가정교육과 교수 2

Objectives: The purpose of this study was to investigate the relationship between emotional awareness and psychological well-being in adolescents with cognitive emotion regulation strategies as mediators.

Methods: A total of 375 middle and high school students in Seoul and Gyeonggi-do participated. Selfreport questionnaires were used to assess their emotional awareness, adaptive and maladaptive emotion regulation strategies, and psychological well-being. The data were analyzed using descriptive statistics, Pearson's correlations, and regression analyses in PROCESS macro.

Results: First, emotional awareness was related to both cognitive emotion regulation strategies and psychological well-being. Also, adaptive strategies for regulating emotions were strongly related to psychological well-being, while maladaptive strategies were inversely related to psychological wellbeing. Second, both adaptive and maladaptive emotion regulation strategies partially mediated the link between emotional awareness and psychological well-being in adolescents.

Conclusions: These findings indicate that emotional awareness and cognitive emotion regulation strategies are important factors in improving the psychological well-being of adolescents.

Keywords: emotional awareness, cognitive emotion regulation strategies, psychological well-being, adolescents

\section{Introduction}

청소년기는 아동기에서 성인기로 향하는 과도기로, 다양한 측 면에서 급격한 변화가 나타나는 시기이다. 청소년들은 점차 부모로부터 독립을 준비하고, 자신의 고유한 정체성을 형성

Corresponding Author: JungHa Lim, Professor, Department of Home Economics, College of Education, Korea University, 145 Anam-ro, Seongbuk-gu, Seoul, Korea

E-mail: jhlim@korea.ac.kr
해가는 동시에 새로운 학교 환경에도 적응해야 한다. 특히 중 고등학생들의 경우, 진로 탐색 및 결정에 대한 부담이 가중되 며 본격적인 입시 경쟁을 직면하게 된다. 더불어 다수의 중고 등학생들은 대학 진학을 위해 현재의 안녕감을 유예하는 것 이 당연시되는 사회적 분위기를 경험하기도 한다. 이와 같이

(C)The Korean Association of Child Studies

This is an Open Access article distributed under the terms of the Creative Commons Attribution Non-Commercial License (http:// creativecommons.org/licenses/by-nc/4.0) which permits unrestricted noncommercial use, distribution, and reproduction in any medium, provided the original work is properly cited. 
청소년기는 상대적으로 안녕감을 위협하는 스트레스원이 많 은 시기이다(Hong \& Park, 2017). 실제로 안녕감의 연령별 비 교연구 결과, 청소년 집단의 안녕감이 대학생 집단에 비해 현 저히 낮은 것으로 나타났다(Han et al., 2012). 안녕감은 청소년 기의 긍정적 발달에 중요한 역할을 할 뿐만 아니라 이후 성인 기의 적응에도 영향을 줄 수 있으므로(Song \& Jo, 2018; Yun \& Lee, 2016), 청소년의 심리적 안녕감에 대한 심도 있는 연구를 통해 효과적인 지원 방안을 모색할 필요가 있다.

심리적 안녕감이란 자신을 있는 그대로 받아들이고, 긍정 적인 대인관계를 유지하며, 자신의 행동을 조절할 수 있고, 환 경에 대한 통제력을 가지며, 삶의 목적이 있고, 자신의 잠재력 을 실현시키고자하는 동기가 있는 상태를 뜻한다(Ryff, 1989). 이는 개인이 사회 구성원으로서 얼마나 잘 기능하고 있는지 를 강조하는 것으로, 주관성을 반영할 뿐만 아니라 여러 이론 을 바탕으로 구성되어 다면성 역시 포함하고 있다(Jun \& Oh, 2011). 특히 우리나라 중고등학생들의 실정에 적합한 심리적 안녕감을 측정하고자 한 연구(J.-H. Park \& Sim, 2007)에 따르 면, 심리적 안녕감은 긍정적 자기인식, 가족관계, 교사관계, 친 구관계, 자기주장성 및 학습주도성으로 구성된다. 이는 청소 년기의 독특한 발달특성과 대부분의 시간을 학교에서 보내는 우리나라 청소년의 교육 현실을 반영한 것으로 볼 수 있다. 따 라서 본 연구에서는 J.-H. Park과 Sim (2007)의 연구에 기초하 여 심리적 안녕감을 자신에 대해 긍정적인 태도를 지니고, 가 족과 교사 및 친구와 원만하고 친밀한 관계를 형성하며, 자신 의 의견을 적절히 표현하고, 삶의 목표와 방향성을 가지고 학 습하는 상태로 정의하고자 한다.

청소년의 심리적 안녕감에 대해 메타분석한 연구(M.-A. Park, Kim, \& Cheon, 2013)에 따르면 부모의 양육태도, 애착 및 사회적 지지 등 다양한 요인이 심리적 안녕감에 영향을 미치 는 것으로 밝혀졌다. 특히 정서인식 능력을 비롯한 정서적 요 인은 심리적 안녕감과 관련된 주요 요인으로 다루어지고 있다 (Jun \& Oh, 2011; Shin, Lee, \& Lee, 2005). 정서는 상황에 수반 되는 반응으로 개인의 생존과 적응을 지원한다는 점에서(J.-Y. Lee \& Kwon, 2006) 심리적 안녕감과 밀접히 연관되어 있기 때 문이다. 정서를 다루는 능력은 개인에 따라 차이가 있으며, 정 신 건강에 중요한 영향을 미치는 것으로 알려져 있다(Salovey \& Mayer, 1990). 그 중에서도 정서인식 능력은 정서정보처리 과정의 기초로(Mayer, Salovey, Caruso, \& Sitarenios, 2001), 정서 적 정보를 효율적으로 활용할 수 있도록 하여 심리적 안녕감 을 향상시킬 수 있다는 점에서 주목할 필요가 있다.

정서인식 능력이란 자신과 타인의 정서 상태를 정확하
게 파악하고 정의하는 능력을 뜻한다(Ciarrochi, Heaven, \& Supavadeeprasit, 2008). 이는 주의를 통해 획득한 정보를 조합 하여 구체적인 정서와 그 원인이 무엇인지까지 이해할 수 있 는 것을 의미한다(Barrett, Mesquita, Ochsner, \& Gross, 2007). 선행 연구에 의하면, 정서인식 능력은 개인이 긍정적으로 기 능할 수 있도록 지원하여 삶의 의미 및 만족도 수준에 영향을 미치고(Abeyta, Routledge, Juhl, \& Robinson, 2015; Extremera \& Fernádez-Berrocal, 2005), 나아가 심리적 안녕감을 향상시키는 것으로 나타났다(Ciarrochi, Kashdan, Leeson, Heaven, \& Jordan, 2010; J.-O. Lim \& Chang, 2003). 즉 개인은 정서인식 능력을 바탕으로 자신의 욕구나 필요가 충족되고 있는지에 대한 정서 적 정보를 명확히 인지할 수 있고, 이는 다시 적절한 후속 행동 을 선택하는 데 영향을 주어(Boden \& Berenbaum, 2011) 심리 적 안녕감을 증진시킬 수 있다. 실제로 정서인식 능력이 높은 사람들은 문제 해결을 위한 행동을 상대적으로 더 많이 시도 하였을 뿐만 아니라 성취 수준도 높은 것으로 밝혀졌다(Otto \& Lantermann, 2005). 또한 정서인식 능력을 토대로 자신이 주 로 경험하는 정서가 무엇인지 규명함으로써 자기이해를 증 진시킬 수 있으며(S.-J. Lee \& Lee, 1997), 심리적 적응에 도움 이 될 수 있다(H.-Y. Choi, Lee, \& Min, 2008). 나아가 KennedyMoore, Greenberg와 Wortman (1991)이 제안한 정서표현 과정 모형에 근거하여 정서처리과정 유형과 심리적 안녕감의 관계 를 살펴본 연구(Jun \& Oh, 2011)에 따르면, 정서인식 능력이 높은 집단이 낮은 집단에 비해 심리적 안녕감이 높았다. 정서 인식 능력은 스트레스에 대한 완충 역할을 하여 심리적 안녕 감을 유지하게 만드는 것으로 보인다(Jung, 2018). 이상의 연 구결과들은 정서인식 능력이 심리적 안녕감과 관련된 중요한 요인임을 시사한다.

선행 연구들(Augusto-Landa, Pulido-Martos, \& Lopez-Zafra, 2011; J.-O. Lim \& Chang, 2003)은 정서인식 능력과 심리적 안 녕감의 관련성을 밝히는데 기여하였으나, 정서인식 능력에 있 어 타인정서인식을 제외한 자기정서인식에만 초점을 두었다 는 한계가 있다. 본질적으로 심리적 안녕감은 개인이 사회 구 성원으로서 얼마나 잘 기능하고 있는지를 반영한다는 점에서 (Ryff, 1989), 자기정서인식과 더불어 타인정서인식도 함께 살 펴볼 필요가 있다. 타인정서인식은 개인이 사회적 맥락을 이 해하는 데 도움을 주고, 나아가 다양한 상호작용 상황에서 적 절히 대처할 수 있도록 하여(Chang \& Kim, 2011) 심리적 안녕 감에 중요한 역할을 할 수 있다. 따라서 본 연구에서는 자기정 서인식과 타인정서인식을 모두 포함한 정서인식 능력이 심리 적 안녕감에 미치는 영향을 알아보고자 한다. 나아가 청소년 
을 대상으로 정서인식 능력이 어떠한 기제를 통하여 심리적 안녕감에 영향을 미치는지 탐색한 연구는 아직 부족한 실정이 므로, 정서인식 능력과 심리적 안녕감의 관계를 매개하는 요 인에 대해 상세히 살펴보고자 한다.

일각에서는 정서인식 능력이 심리적 안녕감 향상에 중요한 요인이기는 하나, 결정적인 요인으로는 볼 수 없다고 주장한 다(J.-O. Lim \& Chang, 2003). 즉 우수한 정서인식 능력이 반드 시 높은 심리적 안녕감으로 이어지는 것은 아니며, 개인의 특 성에 따라 두 요인 간의 관계가 달라질 수 있다고 지적하였다. 특히 정서인식 능력을 통해 인지된 정서가 어떻게 조절되느 냐에 따라 상이한 결과가 나타날 수 있다는 점에서(S.-J. Lee \& Hyun, 2008), 정서인식 능력과 심리적 안녕감 간의 관계를 매 개할 수 있는 요인으로 인지적 정서조절 전략에 주목할 필요 가 있다. 정서는 유용하고 적응적인 가치를 가지고 있지만, 적 절히 조절하지 못할 경우에는 심리적 고통을 야기하거나 합리 적인 기능을 손상시킬 위험이 있다. 정서를 유발한 자극이나 상황을 어떻게 해석하느냐는 정서조절에서 중요한 역할을 하 므로(Gross, 2002), 적절한 정서조절 전략을 사용하는 것은 성 공적인 정서조절을 가능하게 하여 정서인식 능력과 심리적 안 녕감 간의 관계를 매개할 수 있다. 즉 인지적 정서조절 전략은 정서에 압도당하지 않고 지속적으로 통제하는 능력과 관련되 어 있으며, 정서 경험의 속성이나 강도를 변화시킬 수 있기 때 문에(Garnefski \& Kraaij, 2018) 정서인식 능력과 심리적 안녕 감 간의 관계에서 매개 역할을 할 것으로 보인다.

인지적 정서조절 전략이란 정서적으로 각성된 정보를 다루 는 인지적인 방식을 뜻한다(Thompson, 1991). 이는 인지적 대 처와 유사한 개념으로(Garnefski, Kraaij, \& Spinhoven, 2001), 정 서를 유발한 사건에 대한 인지적인 반응으로 볼 수 있다(Aldao $\&$ Nolen-Hoeksema, 2010). 개인마다 자주 사용하는 인지적 정 서조절 전략은 각기 다르며, 특정 전략들은 보다 기능적으로 작용할 수 있다(Garnefski et al., 2002). Garnefski 등(2001)은 인 지적 정서조절 전략을 적응적 전략과 부적응적 전략으로 구분 하였다. 적응적 전략은 수용, 해결중심사고, 균형있게 바라보 기, 긍정적 재초점, 긍정적 재평가를 포함한다. 즉 적응적 정서 조절 전략은 정서유발 사건을 자신의 경험으로 수용하거나, 문제해결 계획을 세우거나, 다른 사건과 비교하여 심각성을 경감시키거나, 즐거운 일을 생각하거나, 긍정적 의미를 찾는 전략이라고 할 수 있다. 부적응적 전략은 자기 비난, 타인 비 난, 반추, 파국화를 포함한다. 부적응적 정서조절 전략은 곧 정 서를 유발한 사건에 대해 자신 또는 타인의 실수를 생각하거 나, 반복적인 생각을 하거나, 공포스러운 측면을 강조하는 전
략을 말한다. 선행 연구에서 적응적 정서조절 전략은 스트레 스를 완화하는 등 긍정적 결과와 관련되나(S.-H. Kim, 2008), 부적응적 정서조절 전략은 내재화 및 외현화 문제를 심화시키 거나 자살 생각을 증가시키는 등 부정적 결과와 연관되는 것 으로 나타났다(W.-K. Choi \& Kim, 2012; Garnefski, Kraaij, \& Etten, 2005). 따라서 정서인식 능력과 심리적 안녕감 간의 관 계에서도 어떤 인지적 정서조절 전략을 사용하느냐에 따라 상 반된 결과가 나타날 것으로 예측할 수 있다.

대학생을 대상으로 한 연구(S.-J. Lee \& Hyun, 2008; S. Yoo, 2014)에 따르면, 인지적 정서조절 전략은 정서인식 능 력의 영향을 받는 요인이자 심리적 안녕감에 관여하는 것으 로 나타났다. 구체적으로 정서인식 능력은 정서적 정보를 효 과적으로 활용할 수 있도록 한다는 전제하에 적응적 정서조 절 전략을 더 많이 선택하게 하는 것으로 밝혀졌다(Barrett, Gross, Christensen, \& Benvenuto, 2001; Y. Kim, 2014; Nam \& Park, 2017). 부적응적 정서조절 전략은 부정적으로 왜곡된 해 석을 하게 하여 심리적 안녕감을 저하시키는 것에 비해, 적 응적 정서조절 전략은 각각의 상황에 유연하게 대처할 수 있도록 하여 심리적 안녕감을 향상시킬 수 있다(Balzarotti, Biassoni, Villani, Prunas, \& Velotti, 2016; H. W. Kim \& Oh, 2016; Mahmoudzadeh, Mohammadkhani, Dolatshahi, \& Moradi, 2015). 이와 유사한 맥락에서 자신의 정서를 정확히 파악할 수 있는 대학생들은 정서유발 사건에 대해 긍정적 재해석 등과 같은 적응적인 방식으로 대처하여 안녕감을 증진시키는 것으 로 나타났다(Gohm \& Clore, 2002). 더불어 명확한 정서인식 이 정신건강에 미치는 영향에서 인지적 정서조절 전략의 매 개효과를 살펴본 연구(S.-J. Lee \& Hyun, 2008)에서도 부적응 적 정서조절 전략은 주관적 안녕감을 저하시킨 반면, 적응적 정서조절 전략은 주관적 안녕감을 향상시켰다. 이상의 연구 결과들을 바탕으로 볼 때, 개인의 안녕감은 경험에 대한 해석 및 평가와 같은 인지과정에 따라 차이가 날 수 있다는 점에서 (Lyubomirsky, 2001) 인지적 정서조절 전략은 정서인식 능력과 심리적 안녕감의 관계를 매개할 것으로 보인다. 이에 따라 본 연구에서는 심리적 안녕감에 대한 정서인식 능력과 인지적 정 서조절 전략의 영향을 파악해보고, 정서인식 능력이 인지적 정서조절 전략을 매개로 심리적 안녕감에 이르는 경로를 살펴 보고자 한다.

종합하면, 본 연구는 청소년의 정서인식 능력과 심리적 안 녕감의 관계에서 인지적 정서조절 전략의 매개효과를 검증하 고자 한다. 이를 위해 먼저 청소년의 정서인식 능력, 인지적 정 서조절 전략 및 심리적 안녕감의 일반적인 경향을 알아본 후, 
정서인식 능력과 인지적 정서조절 전략 및 심리적 안녕감 간 에 관계가 있는지 살펴볼 것이다. 나아가 인지적 정서조절 전 략이 정서인식 능력과 심리적 안녕감 간의 관계를 매개하는 역할을 하는지 확인해보고자 한다. 이를 통해 청소년의 심리 적 안녕감을 향상시키기 위해 어떠한 지원이 필요한지에 대한 정보를 제공할 수 있을 것으로 기대한다.

\section{연구문제 1}

청소년의 정서인식 능력, 인지적 정서조절 전략 및 심리적 안 녕감은 관계가 있는가?

\section{연구문제 2}

청소년의 정서인식 능력과 심리적 안녕감 간의 관계를 인지 적 정서조절 전략이 매개하는가?

\section{Methods}

\section{연구대상}

본 연구는 서울과 경기 지역에 소재한 8 개 중.고등학교에 재 학 중인 청소년 375 명을 대상으로 실시되었다. 청소년의 연 령 범위는 청소년 기본법상 9 세 이상 24 세 이하 등 각각의 법 적 기준에 따라 상이하게 규정되고 있으나, 본 연구에서는 중 고등학생을 대상으로 하였다. 중고등학생 시기는 경쟁 지향 적인 교육 환경에 따라 학업 성취에 대한 부담이 높고(M. Lee, 2014), 이로 인해 더 많은 스트레스와 갈등을 경험하게 되어 심리적 안녕감을 위협할 수 있다는 점(Hong \& Park, 2017)에 근거하여 본 연구의 대상을 중고등학생으로 선정하였다. 연구 대상의 평균 연령은 16.71 세 $(S D=1.09)$ 였다. 연구대상 중 남 학생이 190 명(50.7\%), 여학생이 185 명(49.3\%)이었다. 학교급 별로 볼 때 중학생이 174 명(46.4\%), 고등학생이 201명(53.6\%) 이었다. 부모의 교육수준은 아버지와 어머니 모두 대학교 졸 업(부: $51.7 \%$; 모: $52.0 \%$ )이 가장 많았다. 아버지의 직업은 사 무관리직(33.1\%)이, 어머니의 직업은 가정주부(27.2\%)가 가 장 많은 것으로 나타났다.

\section{연구도구}

본 연구에서는 정서인식 능력 척도, 인지적 정서조절 전략 척 도 및 심리적 안녕감 척도를 사용하였으며, 모두 청소년의 자
기보고로 측정하였다.

$$
\text { 정서인식 능력 척도 }
$$

정서인식 능력을 측정하기 위하여 Wong과 Law (2002)의 Wong and Law Emotional Intelligence Scale (WLEIS)을 Lim (2014)이 번안하고 타당화한 척도를 사용하였다. 이 척도는 자 기정서인식(4문항), 타인정서인식(4문항), 정서활용(4문항), 정서조절(4문항) 4 개 하위요인으로 구성되어 있다. 본 연구에 서는 자신과 타인의 정서 상태를 정확히 지각하고 이해하는 정도를 측정하기 위하여 자기정서인식(4문항)과 타인정서인 식(4문항)의 2 개 하위요인 총 8 문항만을 사용하였다. 이 척도 는 5점 Likert 척도로, 전혀 그렇지 않다(1점)에서 매우 그렇다 (5점)까지 응답하게 되어있다. 가능한 점수의 범위는 8-40점 이며, 점수가 높을수록 정서인식 능력이 우수한 것으로 해석 한다. 본 연구에서 Cronbach's $\alpha$ 는 전체 문항 .73, 자기정서인 식 요인 .76, 타인정서인식 요인 .71로 나타났다.

\section{인지적 정서조절 전략 척도}

인지적 정서조절 전략을 측정하기 위해 Garnefski, Kraaij 와 Spinhoven (2001)이 개발한 Cognitive Emotion Regulation Questionnaire (CERQ)를 S.-H. Kim (2004)이 번안하고, Ahn, Lee와 Joo (2013)가 타당화한 척도를 사용하였다. 이 척도는 총 35 문항이며, 9 개 하위요인으로 구성되어 있다. 각 하위요인들 은 이론적으로 적응적 정서조절 전략과 부적응적 정서조절 전 략으로 구분된다. 적응적 정서조절 전략에는 수용(acceptance, 3 문항), 해결중심사고(refocus on planning, 4문항), 균형 있게 바 라보기(putting into perspective, 4문항), 긍정적 재초점(positive refocusing, 4문항), 긍정적 재평가(positive reappraisal, 4문항) 요 인이 포함되고, 부적응적 정서조절 전략에는 자기 비난(selfblame, 4문항), 타인 비난(other-blame, 4문항), 반추(rumination, 4 문항), 파국화(catastrophizing, 4 문항) 요인이 포함된다. 각 항 목은 5점 Likert 척도로, 거의 그렇지 않다(1점)에서 거의 항상 그렇다(5점)까지 평정하게 된다. 점수가 높을수록 해당 전략을 더 많이 사용하는 것을 의미한다. 본 연구에서 Cronbach's $\alpha$ 는 적응적 정서조절 전략 .89 , 부적응적 정서조절 전략. 77 이었다.

\section{심리적 안녕감 척도}

심리적 안녕감을 측정하기 위하여 J.-H. Park과 Sim (2007) 
이 개발하고 타당화한 Adolescent Psychological Well-Being Inventory (APWI)를 사용하였다. 이 척도는 총 51문항으로, 긍 정적 자기인식(12문항), 가족관계(12문항), 교사관계(10문항), 친구관계(8문항), 자기주장성(5문항), 학습주도성(4문항)의 6 개 하위요인으로 구성되어 있다. 이 척도는 4점 Likert 척도로, 전혀 그렇지 않다(1점)에서 매우 그렇다(4점)까지 응답하게 되어 있다. 가능한 점수의 범위는 51-204점까지이며, 점수가 높을수록 심리적 안녕감이 높은 것을 의미한다. 본 연구에서 산출된 Cronbach's $\alpha$ 는 전체 문항 .96이었고, 하위요인별로 .74 $\sim .92$ 로 나타났다.

\section{연구절차}

본조사에 앞서 서울 및 경기도에 소재한 중학교와 고등학교 2 곳의 3학급에서 재학 중인 청소년 73명을 대상으로 예비조사 를 실시하였다. 이를 통해 설문지의 타당성과 절차상의 문제 여부 등을 검토하였고, 설문지 작성에 관한 안내를 보완하였 다. 본조사는 2018년 3월, 서울 및 경기도의 4개 중학교와 4개 고등학교에 재학 중인 청소년 390 명을 대상으로 편의 표집하 여 실시하였다. 조사 대상 기관에는 사전에 연구 목적과 설문 방법을 설명하여 협조를 구하였고, 교사와 학생들에게 연구 내용과 비밀보장 및 사생활 보호의 원칙에 관해 안내하였다. 설문지 배부 전, 연구 참여에 대한 의사를 구두로 물은 후 이에 자발적으로 동의한 학생에 한해 설문을 실시하였다. 설문의 소요시간은 약 20 분이었고, 참여 학생과 협조 교사에게는 감 사의 표시로 답례품을 전달하였다. 배부된 설문지는 모두 회 수되었으며, 응답이 누락된 자료를 제외한 375부(96.15\%)를 자료분석에 사용하였다.

\section{자료분석}

본 연구에서 수집된 자료는 SPSS 23.0 (IBM Co., Armonk, NY) 을 사용하여 분석하였다. 구체적인 자료분석 방법은 다음과 같다. 첫째, 연구대상자의 일반적인 특성을 알아보기 위해 빈 도분석을 실시하였다. 또한 청소년의 정서인식 능력, 인지적 정서조절 전략 및 심리적 안녕감의 일반적인 경향을 알아보기 위해 평균과 표준편차를 산출하였다. 둘째, 청소년의 정서인 식 능력과 인지적 정서조절 전략 및 심리적 안녕감의 관련성 을 알아보기 위해 상관분석을 실시하였다. 끝으로, 청소년의 정서인식 능력과 심리적 안녕감 간의 관계에서 인지적 정서 조절 전략의 매개효과를 살펴보기 위해 Hayes (2017)가 제시 한 PROCESS macro version 3.0 (Model 4)을 사용하여 다중매 개 분석을 실시하였다. 다중매개 분석 이후 매개효과의 통계 적 유의성 검증을 위해 5000회의 부트스트래핑(bootstrapping) 을 실시하였다.

\section{Results}

\section{청소년의 정서인식 능력과 인지적 정서조절 전략 및 심리적 안녕감의 관계}

청소년의 정서인식 능력과 인지적 정서조절 전략 및 심리적 안녕감이 어떠한 경향을 보이는지 살펴보기 위해 평균과 표준 편차를 산출하고, 변인 간의 관계를 알아보기 위해 Pearson 적 률상관계수를 산출하였다(Table 1).

청소년의 정서인식 능력은 심리적 안녕감과 중간정도 크기 의 정적 상관이 있는 것으로 나타났다 $(r=.50, p<.001)$. 즉, 청

Table 1

Correlations Among Emotional Awareness, Cognitive Emotion Regulation Strategies, and Psychological Well-Being

\begin{tabular}{|c|c|c|c|c|}
\hline & 1 & 2 & 3 & 4 \\
\hline 1. Emotional awareness & - & $.41^{* * *}$ & $-.20^{* * *}$ & $.50^{* * *}$ \\
\hline \multicolumn{5}{|c|}{ Cognitive emotion regulation strategies } \\
\hline 2. Adaptive strategies & & - & $.15^{* *}$ & $.53^{* * *}$ \\
\hline 3. Maladaptive strategies & & & - & $-.24^{* * *}$ \\
\hline 4. Psychological well-being & & & & - \\
\hline$M$ & 3.80 & 3.32 & 2.87 & 3.04 \\
\hline$S D$ & .48 & .63 & .51 & .44 \\
\hline
\end{tabular}

Note. $N=375$.

${ }^{* *} p<.01 .{ }^{* * *} p<.001$. 
소년이 자신과 타인의 정서 상태를 정확히 지각할수록 심리적 안녕감이 높았다. 또한 청소년의 정서인식 능력은 적응적 정 서조절 전략 $(r=.41, p<.001)$ 과는 정적 상관을 보였고, 부적응 적 정서조절 전략 $(r=-.20, p<.001)$ 과 부적 상관을 나타냈다. 즉 청소년이 자신과 타인의 정서를 정확하게 인지할수록 적 응적인 정서조절 전략을 사용하며, 자신과 타인의 정서를 명 확히 지각하지 못할수록 부적응적인 정서조절 전략을 사용하 는 것으로 나타났다. 또한 정서인식 능력은 부적응적 정서조 절 전략보다 적응적 정서조절 전략과 더 강한 상관관계가 있 었다. 끝으로 적응적 정서조절 전략은 심리적 안녕감 $(r=.53$, $p$ <.001)과 유의한 정적 상관이 있었으며, 부적응적 정서조절 전략은 심리적 안녕감 $(r=-.24, p<.001)$ 과 유의한 부적 상관이 있는 것으로 나타났다. 즉 청소년이 정서를 유발한 사건에 대 해 적응적인 정서조절 전략을 사용할수록 심리적 안녕감이 높 았고, 부적응적인 정서조절 전략을 사용할수록 심리적 안녕감 이 낮은 것으로 나타났다.

\section{청소년의 정서인식 능력과 심리적 안녕감 간의 관계에서 인지적 정서조절 전략의 매개효과}

청소년의 정서인식 능력과 심리적 안녕감 간의 관계에서 인 지적 정서조절 전략의 하위요인인 적응적 정서조절 전략 및 부적응적 정서조절 전략이 매개하는지 알아보기 위해 Hayes (2017)가 제안한 다중 매개모형 분석을 실시하였다. 그 결과는 Table 2와 Figure 1에 제시한 바와 같다.

Hayes (2013/2015)의 제안에 따라 분석결과는 비표준화 계 수로 제시하였으며, 이를 바탕으로 다중 매개효과 분석 시의 세 가지 조건이 충족되는지 확인하였다. 첫째, 독립변인에서 종속변인으로 가는 경로와 독립변인에서 매개변인으로 가는 경로 및 매개변인에서 종속변인으로 가는 경로가 통계적으로

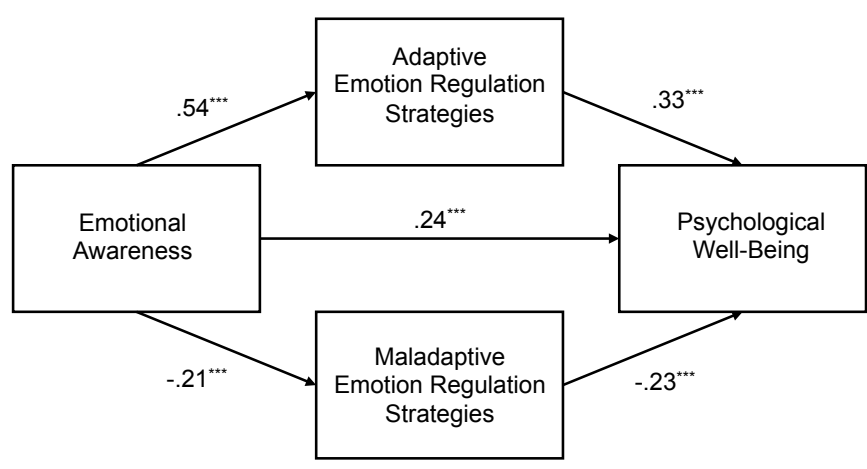

Figure 1. Model of cognitive emotion regulation strategies as mediators of the relationship between emotional awareness and psychological well-being.

${ }^{* * *} p<.001$.

유의한지 살펴보았다. 둘째, 독립변인이 단독으로 투입되었을 때의 직접 효과의 크기가 독립변인과 매개변인이 동시에 투입 되었을 때 독립변인이 종속변인을 설명하는 직접 효과의 크기 에 비해 유의미하게 감소하였는지 확인하였다. 마지막으로, 부트스트랩핑 방식을 사용하여 매개효과가 통계적으로 유의 한지 검증하였다.

첫 번째 모형에서 정서인식 능력이 심리적 안녕감에 미치 는 영향력이 유의한 것으로 나타났다 $(b=.46, p<.001)$. 두 번 째 모형에서 정서인식 능력이 적응적 정서조절 전략에 미치 는 영향력이 통계적으로 유의하였다 $(b=.54, p<.001)$. 세 번 째 모형에서 정서인식 능력이 부적응적 정서조절 전략에 미치 는 영향력 또한 유의한 것으로 나타났다 $(b=-.21, p<.001)$. 끝 으로, 네 번째 모형에서 정서인식 능력 $(b=.24, p<.001)$ 과 적 응적 정서조절 전략 $(b=.33, p<.001)$ 및 부적응적 정서조절 전 략 $(b=-.23, p<.001)$ 이 심리적 안녕감에 미치는 영향력이 통 계적으로 유의하였다. 또한 정서인식 능력과 인지적 정서조절 전략이 동시에 투입되었을 때 정서인식 능력이 심리적 안녕감

Table 2

Cognitive Emotion Regulation Strategies as Mediators of the Relationship Between Emotional Awareness and Psychological Well-Being

\begin{tabular}{clccccc}
\hline Model & \multicolumn{1}{c}{ Path } & $b$ & $S E$ & $t$ & $R^{2}$ & $F$ \\
\hline 1 & Emotional awareness $\rightarrow$ Psychological well-being & .46 & .04 & $11.03^{* * *}$ & .25 & $121.56^{* * *}$ \\
\hline 2 & Emotional awareness $\rightarrow$ Adaptive strategies & .54 & .06 & $8.57^{* * *}$ & .16 & $73.46^{* * *}$ \\
\hline 3 & Emotional awareness $\rightarrow$ Maladaptive strategies & -.21 & .05 & $-3.83^{* * *}$ & .04 & $14.70^{* * *}$ \\
\hline 4 & Emotional awareness $\rightarrow$ Psychological well-being & .24 & .04 & $5.79^{* * *}$ & .44 & $95.22^{* * *}$ \\
& Adaptive strategies $\rightarrow$ Psychological well-being & .33 & .03 & $10.51^{* * *}$ & \\
& Maladaptive strategies $\rightarrow$ Psychological well-being & -.23 & .04 & $-6.26^{* * *}$ &
\end{tabular}

Note. $N=375$.

*** $p<.001$. 
Table 3

Confidence Limits of Significance of the Mediating Effects

\begin{tabular}{|c|c|c|c|c|c|}
\hline & & Effect & $S E$ & LLCI & ULCI \\
\hline Total effect & & .46 & .04 & .38 & .55 \\
\hline Direct effect & & .24 & .04 & .16 & .32 \\
\hline \multirow[t]{3}{*}{ Indirect effect } & Total & .22 & .03 & .17 & .29 \\
\hline & Path1 & .18 & .03 & .12 & .24 \\
\hline & Path2 & .05 & .02 & .02 & .08 \\
\hline
\end{tabular}

Note. Path $1=$ emotional awareness $\rightarrow$ adaptive strategies $\rightarrow$ psychological well-being;

Path2 $=$ emotional awareness $\rightarrow$ maladaptive strategies $\rightarrow$ psychological well-being

에 미치는 영향력은 줄어들었으며 $(b=.46, p<.001 \rightarrow b=.24, p$ <.001), 모형의 설명력은 추가적으로 $19 \%$ 증가하였다. 즉 청 소년의 정서인식 능력과 심리적 안녕감 간의 관계를 인지적 정서조절 전략이 부분적으로 매개하는 것으로 나타났다. 이 와 같은 부분 매개효과가 통계적으로 유의한지 살펴보기 위해 5000 회의 부트스트래핑을 실시하였고, $95 \%$ 신뢰구간을 적용 하였다. 그 결과는 Table 3에 제시한 바와 같다.

먼저 정서인식 능력이 심리적 안녕감에 미치는 직접효과는 $.24(.16, .32)$ 로, 통계적으로 유의했다. 다음으로 경로 1 의 간접 효과는 $.18(.12, .24)$, 경로2의 간접효과 역시 $.05(.02, .08)$ 로 통 계적으로 유의했다. 즉, 정서인식 능력과 심리적 안녕감 간의 관계에서 적응적 정서조절 전략과 부적응적 정서조절 전략 모 두 통계적으로 유의한 부분 매개효과를 보였다. 이들 간접효 과의 크기를 상대적으로 비교해 보면, 적응적 정서조절 전략 을 매개로 한 간접효과가 .18 로 부적응적 정서조절 전략을 매 개로 한 간접효과인 .05에 비해 크게 나타났다. 이러한 두 간접 효과의 차이가 유의미한 것인지 확인하기 위해 부트스트래핑 방식으로 $95 \%$ 신뢰구간을 산출한 결과 $(.06, .20)$ 으로 나타났 다. 즉, 정서인식 능력과 심리적 안녕감 간의 관계에서 부적응 적 정서조절 전략보다 적응적 정서조절 전략을 매개로 한 경 로가 더욱 큰 영향력을 가지는 것으로 해석할 수 있다.

\section{Discussion}

본 연구는 청소년의 인지적 정서조절 전략이 정서인식 능력과 심리적 안녕감 간의 관계를 매개하는지 살펴보기 위해 실시되 었다. 이를 위해 정서인식 능력과 인지적 정서조절 전략 및 심 리적 안녕감 간의 관계를 알아보고, 정서인식 능력과 심리적 안녕감 간의 관계에서 인지적 정서조절 전략의 매개효과를 분 석하였다. 본 연구의 주요결과에 대한 논의는 다음과 같다.
첫째, 청소년의 정서인식 능력과 인지적 정서조절 전략 및 심리적 안녕감은 밀접한 관련이 있는 것으로 나타났다. 먼저 정서인식 능력은 심리적 안녕감과 유의한 정적 상관을 보였 다. 이는 청소년이 자신과 타인의 정서를 정확하게 지각할수 록 심리적 안녕감이 높음을 의미한다. 이러한 결과는 정서인 식 능력이 높을수록 심리적 안녕감이 높다는 연구들(AugustoLanda et al., 2011; M.-J. Lee, 2013)과 일치한다. 또한 청소년을 대상으로 한 연구(Jun \& Oh, 2011)에서 정서인식 능력이 높은 집단이 낮은 집단에 비해 심리적 안녕감이 높았다는 결과와도 같은 맥락에 있다. 이는 자신과 타인의 정서 상태를 구체적으 로 파악할 수 있는 능력이 청소년의 심리적 안녕감과 관련이 있음을 보여준다. 정서인식 능력은 정서적 정보를 효율적으로 활용할 수 있게 하는 기초로, 상황에 적절한 후속 행동을 결정 하는 데 영향을 준다. 청소년은 명확한 정서인식 능력을 토대 로 자신의 욕구나 필요를 충족시킬 수 있는 행동을 할 수 있고, 이는 궁극적으로 심리적 안녕감 향상으로 이어질 수 있는 것 으로 보인다. 나아가 자신의 정서뿐만 아니라 타인의 정서 상 태 역시 정확히 지각하고, 그 정서적 맥락을 이해할 수 있는 사 람은 사회적 상호작용에서 보다 기능적으로 행동할 수 있기에 심리적 안녕감이 높게 나타난 것으로 보인다. 따라서 청소년 의 심리적 안녕감과 관련하여 명확한 정서인식 능력의 중요성 을 강조할 필요가 있다. 특히 정서인식 능력이 가변적인 속성 을 지니고 있다는 점을 고려할 때, 심리적 안녕감 증진을 위해 청소년들이 정서를 정확하게 지각할 수 있도록 돕는 교육이 제공되어야 할 것이다.

다음으로 청소년의 정서인식 능력과 인지적 정서조절 전 략은 긴밀한 관련이 있는 것으로 나타났다. 즉 정서인식 능력 은 적응적 정서조절 전략과는 정적 상관을 보이고, 부적응적 정서조절 전략과는 부적 상관이 있었다. 이러한 결과는 정서 를 명확히 인식하는 능력이 높을수록 적응적 정서조절 전략을 더 많이 사용하고, 부적응적 정서조절 전략을 적게 사용하는 
것으로 보고한 연구(Y. Kim, 2014; S.-J. Lee \& Hyun, 2008)와 일치한다. 더불어 정서의 원인이나 맥락, 결과에 대한 이해가 부족하면 정서를 적절히 조절하지 못한다는 연구(Eastabrook, Flynn, \& Hollenstein, 2014), 낮은 정서인식 능력이 정서경험 을 건설적인 방식으로 관리하는 능력을 약화시킨다는 연구 (Saarni, 2000)와도 맥을 같이 한다. 또한 S. Kim과 Min (2006) 의 연구에 따르면, 동일한 상황에서 정서인식 능력이 높은 집 단에 비해 낮은 집단은 자신이 어떤 정서 상태인지 명확히 이 해하지 못하여 해당 상황과 크게 관련이 없는 부정 정서까지 강하게 경험하게 되는 것으로 나타났다. 즉 슬퍼해야 할 것인 지, 화를 내야 할 것인지 등을 판단하지 못하고 혼란스러워하 며 효과적으로 대처하지 못하게 된다는 것이다. 이처럼 정서 인식 능력이 부족한 사람들은 자신이 정서적 고통을 경험하 고 있다는 것은 알지만 정확히 어떤 정서 상태인지 인식하지 못하기 때문에(Penza-Clyve \& Zeman, 2002) 효과적인 정서조 절 전략을 사용하지 못할 수 있다. 반면, 정서인식 능력이 높 은 사람은 자신이 가진 제한된 주의량을 대처과정으로 전환하 여 긍정적인 사고와 행동을 촉진시킬 수 있으므로(Swinkels \& Giuliano, 1995), 보다 적절하고 효율적인 방법으로 정서를 조 절하고자 하는 시도를 하는 것으로 추론해 볼 수 있다.

끝으로, 청소년의 인지적 정서조절 전략과 심리적 안녕감 은 밀접한 관련이 있는 것으로 나타났다. 구체적으로 적응적 정서조절 전략은 심리적 안녕감과 정적 상관이 있는 반면, 부 적응적 정서조절 전략은 심리적 안녕감과 부적 상관을 보였 다. 이러한 결과는 적응적 전략은 심리적 안녕감을 향상시키 지만, 부적응적 전략은 심리적 안녕감을 저해한다는 다수의 연구들(Balzarotti et al., 2016; H. W. Kim \& Oh, 2016; Panahi et al., 2016; S. Yoo, 2014)과 일치한다. 또한 적응 수준이 높은 청 소년이 낮은 청소년에 비해 부적응적 정서조절 전략을 적게 사용한다는 연구(M. Kim \& Kwon, 2008), 문제 해결을 위한 계 획을 수립하는 등의 능동적 정서조절 양식을 사용할수록 심 리적 안녕감이 높았다는 연구(Shin et al., 2005)와도 유사한 맥 락이라고 볼 수 있다. 이는 동일한 사건일지라도 어떤 사고방 식을 통해 정서를 조절하는지가 심리적 안녕감과 긴밀히 관 련되어 있음을 의미한다. 정서조절은 개인이 잠재적인 역량 을 발휘하고, 최적의 상태로 기능하는데 중요한 역할을 한다 (Cicchetti, Ackerman, \& Izard, 1995). 특히 정서조절을 잘 하기 위해서는 정서적 각성을 유발한 원인에 대한 인지적 재해석의 단계가 매우 중요하다(A. J. Yoo, Lee, \& Jung, 2006). 이와 같은 측면에서 인지적 정서조절 전략 중 부적응적 전략은 적응적 전략에 비해 정서유발 사건을 실제보다 부정적으로 왜곡하여
해석하게 한다는 점에서 차이가 있다. 이러한 차이는 궁극적 으로 심리적 안녕감과의 관계에 상이한 영향을 미칠 수 있다. 따라서 상황에 알맞은 정서조절 전략을 습득할 수 있도록 지 원하는 것은 청소년의 심리적 안녕감 증진에 도움이 될 수 있 을 것이다.

둘째, 청소년의 정서인식 능력은 심리적 안녕감에 직접적 인 영향을 미칠 뿐만 아니라 인지적 정서조절 전략을 매개로 심리적 안녕감에 간접적인 영향을 미치는 것으로 나타났다. 이러한 결과는 정서인식 능력과 인지적 정서조절 전략이 청소 년의 심리적 안녕감에 중요한 요인임을 말해준다. 동시에 본 연구의 결과는 정서인식 능력과 심리적 안녕감 간의 관계에서 부적응적 정서조절 전략을 지양하는 것보다 적응적 정서조절 전략을 활용하는 것이 더욱 효과적임을 나타낸다. 이는 심리 적 안녕감이란 부정적인 감정과 경험이 없는 것이 아니라 다 양한 도전이나 어려움을 어떻게 다루고 변화시키는지에 의해 좌우된다는 연구(Ryff \& Singer, 2003)와 맥을 같이 한다. 또한 명확한 정서인식 능력이 정서조절 양식을 매개로 심리적 안녕 감에 간접적인 영향을 미쳤다는 연구결과(J.-O. Lim \& Chang, 2003)와도 유사한 맥락에 있다. 더불어 정서를 정확히 파악하 는 능력이 우수할수록 정서조절에 대한 기대감이 증가하고, 이는 일종의 동기로 작용하여 부적응적 정서조절 전략보다 적 응적 정서조절 전략의 활용을 통해 정신건강을 증진시킨다는 연구결과(S.-J. Lee \& Hyun, 2008)를 지지한다. 따라서 청소년 의 심리적 안녕감을 향상시키기 위해서는 자신과 타인의 정서 상태를 명확히 이해할 수 있도록 다양한 측면에서 접근하며, 가정 또는 학교 현장에서 정서를 구체적으로 구분하고 명명 하는 연습을 독려해야 할 것이다. 특히 정서 단어에 대한 지식 은 세분화된 정서 이해를 가능하게 하므로(E.-S. Choi \& Bang, 2013) 정서 단어를 강조한 교육을 제공할 필요가 있다. 또한 얼굴 표정 사진을 활용한 정서인식 훈련 등을 실시하는 것은 청소년의 심리적 안녕감을 증진시키는 효과적인 방안이 될 수 있다. 나아가 인지적 정서조절 전략의 부분 매개효과는 청소 년의 심리적 안녕감을 향상시키기 위해 상황에 알맞은 정서조 절 전략을 선택하고 활용할 수 있도록 지원해야 함을 시사한 다. 즉, 청소년 자신이 자주 사용하는 인지적 정서조절 전략이 무엇인지 자각하고, 부적응적 정서조절 전략을 적응적 정서조 절 전략으로 대체할 수 있게 돕는 교육 프로그램이 제공되어 야 할 것이다.

덧붙여 본 연구에서 간접효과의 상대적 크기를 비교한 결 과, 인지적 정서조절 전략 중 부적응적 정서조절 전략의 매개 효과보다 적응적 정서조절 전략의 매개효과가 더 큰 것으로 
나타났다. 이러한 결과는 심리적 안녕감에 있어 적응적 정서 조절 전략이 부적응적 정서조절 전략보다 더 많은 영향력을 갖는다고 제시한 연구들(An \& Yoo, 2016; H. W. Kim \& Oh, 2016; H. Park \& Chae, 2012)과 동일한 결과이다. 이는 긍정심 리학의 관점에서 해석해 볼 수 있다(S. Yoo, 2014). 긍정심리 학은 심리적 안녕감 증진에 있어 개인의 결함을 보완하는 방 식만으로는 충분하지 않으며, 강점을 개발하고 함양하는 것 이 더 중요하다고 강조한다(J. Kim \& Kwon, 2015). Heimberg, Acerra와 Holstein (1985) 또한 긍정적 사고가 부정적 사고보다 개인의 적응 기능을 결정짓는 보다 핵심적인 요소라고 주장하 였다. 나아가 심리적 안녕감은 본질적으로 개인의 긍정적 기 능화를 반영하는 개념임을 고려할 필요가 있다. 정리하면, 부 적응적 정서조절 전략에 비해 적응적 정서조절 전략은 정서유 발 사건에 대해 적극적인 대처를 가능하게 한다는 점에서 심 리적 안녕감에 더 큰 영향력을 미치는 것으로 생각해 볼 수 있 다. 즉 부적응적 정서조절 전략은 실제보다 왜곡된 해석을 하 게 하지만, 적응적 정서조절 전략은 정서적 사건으로부터 발 생할 수 있는 유해한 영향을 최소화할 수 있도록 도와 개인이 효과적으로 기능할 수 있도록 한다. 따라서 청소년의 심리적 안녕감을 증진시키기 위해서는 부적응적 정서조절 전략의 사 용을 지양하는 것보다 적응적 정서조절 전략의 활용을 촉진하 는 것이 더욱 효과적인 것으로 보인다.

끝으로 본 연구가 갖는 제한점과 후속연구를 위한 제언은 다음과 같다. 첫째, 본 연구에서는 서울과 경기 지역에 소재한 중- 고등학교의 학생들을 대상으로 표집이 이루어졌다. 따라 서 본 연구의 결과를 모든 청소년에게 일반화하여 설명하는 데에는 한계가 있다. 후속 연구에서는 지역별, 연령별로 더욱 다양한 표집이 이루어져야 할 것이다. 둘째, 본 연구는 자기 보 고식 질문지에 의한 결과이기 때문에 청소년의 정서인식 능력 과 인지적 정서조절 전략 및 심리적 안녕감이 실제보다 과장 되었거나 축소되었을 가능성이 있다. 또한 청소년의 지각으로 측정되었기 때문에 사회적 바람직성이 개입되었을 수 있다. 후속 연구에서는 개인 면담, 부모 평가 등의 여러 측정 방법을 통해 연구의 객관성을 높일 수 있을 것이다. 셋째, 본 연구는 청소년의 정서인식 능력과 인지적 정서조절 전략에 한하여 심 리적 안녕감에 미치는 영향을 탐색하였다. 정서적 변인들은 서로 유기적으로 작용하여 심리적 안녕감에 상이한 영향을 미 칠 수 있다. 추후 연구에서는 정서강도 또는 정서표현성 등을 포함하여 보다 정밀한 정서처리 과정을 살펴보는 것도 이들 관련성 파악에 도움이 될 것이다.

이러한 제한점에도 불구하고 본 연구는 청소년의 정서인식
능력이 심리적 안녕감에 미치는 영향을 검증하였으며, 나아 가 정서인식 능력과 심리적 안녕감 간의 관계에서 인지적 정 서조절 전략의 매개효과를 규명하였다. 더불어 정서인식 능력 에 있어 자기정서인식뿐만 아니라 타인정서인식 역시 고려하 여 심리적 안녕감에 미치는 영향을 살펴보았다는데 의의가 있 다. 또한 인지적 정서조절 전략 중 부적응적 정서조절 전략보 다 적응적 정서조절 전략의 사용을 촉진하는 것이 심리적 안 녕감 향상에 효율적임을 제시하였다. 정서인식 능력을 통해 지각된 정서는 개인의 생존과 적응을 지원하는 정보로서 기능 할 수 있으며, 다만 이러한 정서를 어떻게 조절하는지에 따라 심리적 안녕감 수준이 달라질 것으로 보인다. 따라서 청소년 의 심리적 안녕감을 향상시키기 위해서는 정서인식 능력을 함 양할 뿐만 아니라 상황에 적절한 인지적 정서조절 전략을 활 용할 수 있도록 돕는 다양한 개입 방안을 모색해야 할 것이다.

\section{Notes}

This article is a part of the first author's master's thesis submitted in 2018.

\section{Conflict of Interest}

No potential conflict of interest relevant to this article was reported.

\section{References}

\section{In English}

Abeyta, A. A., Routledge, C., Juhl, J., \& Robinson, M. D. (2015). Finding meaning through emotional understanding: Emotional clarity predicts meaning in life and adjustment to existential threat. Motivation and Emotion, 39(6), 973983. doi:10.1007/s11031-015-9500-3

Aldao, A., \& Nolen-Hoeksema, S. (2010). Specificity of cognitive emotion regulation strategies: A transdiagnostic examination. Behaviour Research and Therapy, 48(10), 974983. doi:10.1016/j.brat.2010.06.002

Augusto-Landa, J. M., Pulido-Martos, M., \& Lopez-Zafra, E. (2011). Does perceived emotional intelligence and optimism/pessimism predict psychological well-being? 
Journal of Happiness Studies, 12(3), 463-474. doi:10.1007/ s10902-010-9209-7

Balzarotti, S., Biassoni, F., Villani, D., Prunas, A., \& Velotti, P. (2016). Individual differences in cognitive emotion regulation: Implications for subjective and psychological well-being. Journal of Happiness Studies, 17(1), 125-143. doi:10.1007/s10902-014-9587-3

Barrett, L. F., Gross, J., Christensen, T. C., \& Benvenuto, M. (2001). Knowing what you're feeling and knowing what to do about it: Mapping the relation between emotion differentiation and emotion regulation. Cognition \& Emotion, 15(6), 713724. doi:10.1080/02699930143000239

Barrett, L. F., Mesquita, B., Ochsner, K. N., \& Gross, J. J. (2007). The experience of emotion. Annual Review of Psychology, 58, 373-403. doi:10.1146/annurev.psych.58.110405.085709

Boden, M. T., \& Berenbaum, H. (2011). What you are feeling and why: Two distinct types of emotional clarity. Personality and Individual Differences, 51(5), 652-656. doi:10.1016/ j.paid.2011.06.009

Ciarrochi, J., Heaven, P. C. L., \& Supavadeeprasit, S. (2008). The link between emotion identification skills and socioemotional functioning in early adolescence: A 1-year longitudinal study. Journal of Adolescence, 31(5), 565-582. doi:10.1016/j.adolescence.2007.10.004

Ciarrochi, J., Kashdan, T. B., Leeson, P., Heaven, P., \& Jordan, C. (2010). On being aware and accepting: A oneyear longitudinal study into adolescent well-being. Journal of Adolescence, 34(4), 695-703. doi:10.1016/ j.adolescence.2010.09.003

Cicchetti, D., Ackerman, B. P., \& Izard, C. E. (1995). Emotions and emotion regulation in developmental psychopathology. Development and Psychopathology, 7(1), 1-10. doi:10.1017/ S0954579400006301

Eastabrook, J. M., Flynn, J. J., \& Hollenstein, T. (2014). Internalizing symptoms in female adolescents: Associations with emotional awareness and emotion regulation. Journal of Child and Family Studies, 23(3), 487-496. doi:10.1007/ s10826-012-9705-y

Extremera, N., \& Fernádez-Berrocal, P. (2005). Perceived emotional intelligence and life satisfaction: Predictive and incremental validity using the Trait Meta-Mood Scale. Personality and Individual Differences, 39(5), 937-948. doi:10.1016/j.paid.2005.03.012

Garnefski, N., \& Kraaij, V. (2018). Specificity of relations between adolescents' cognitive emotion regulation strategies and symptoms of depression and anxiety. Cognition and Emotion, 32(7), 1401-1408. doi:10.1080/02699931.2016. 1232698

Garnefski, N., Kraaij, V., \& Spinhoven, P. (2001). Negative life events, cognitive emotion regulation and emotional problems. Personality and Individual Differences, 30(8), 1311-1327. doi:10.1016/S0191-8869(00)00113-6

Garnefski, N., Kraaij, V., \& van Etten, M. (2005). Specificity of relations between adolescents' cognitive emotion regulation strategies and internalizing and externalizing psychopathology. Journal of Adolescence, 28(5), 619-631. doi:10.1016/j.adolescence.2004.12.009

Garnefski, N., van den Kommer, T., Kraaij, V., Teerds, J., Legerstee, J., \& Onstein, E. (2002). The relationship between cognitive emotion regulation strategies and emotional problems: Comparison between a clinical and a non-clinical sample. European Journal of Personality, 16(5), 403-420. doi:10.1002/per.458

Gohm, C. L., \& Clore, G. L. (2002). Four latent traits of emotional experience and their involvement in well-being, coping, and attributional style. Cognition \& Emotion, 16(4), 495-518. doi:10.1080/02699930143000374

Gross, J. J. (2002). Emotion regulation: Affective, cognitive, and social consequences. Psychophysiology, 39(3), 281-291.

Hayes, A. F. (2017). Introduction to mediation, moderation, and conditional process analysis: A regression-based approach (2nd ed.). New York : Guilford Publications.

Heimberg, R. G., Acerra, M. C., \& Holstein, A. (1985). Partner similarity mediates interpersonal anxiety. Cognitive Therapy and Research, 9(4), 443-453. doi:10.1007/BF01173092

Kennedy-Moore, E., Greenberg, M. A., \& Wortman, C. B. (1991). Varieties of nonexpression: A review of self-report measures of emotional control. Paper presented at 99th Annual Convention of the American Psychological Association, San Francisco, CA.

Lyubomirsky, S. (2001). Why are some people happier than others? The role of cognitive and motivational processes in well-being. American Psychologist, 56(3), 239-249. doi:10.1037/0003-066X.56.3.239

Mahmoudzadeh, S., Mohammadkhani, P., Dolatshahi, B., \& Moradi, S. (2015). Prediction of psychological well-being based on dispositional mindfulness and cognitive emotion regulation strategies in students. Practice in Clinical Psychology, 3(3), 193-200.

Mayer, J. D., Salovey, P., Caruso, D. R., \& Sitarenios, G. (2001). Emotional intelligence as a standard intelligence. Emotion, 1(3), 232-242. doi:10.1037/1528-3542.1.3.232

Otto, J. H., \& Lantermann, E.-D. (2005). Individual differences in emotional clarity and complex problem solving. Imagination, Cognition and Personality, 25(1), 3-24. doi:10.2190/BUDG-Y02K-F254-YBGK

Panahi, S., Yunus, A. S. M., Roslan, S., Kadir, R. A., Jaafar, W. M. W., \& Panahi, M. S. (2016). Predictors of psychological well-being among Malaysian graduates. The European Journal of Social and Behavioural Sciences, 16, 2067-2083. 
doi:10.15405/ejsbs. 186

Penza-Clyve, S., \& Zeman, J. (2002). Initial validation of the Emotion Expression Scale for Children (EESC). Journal of Clinical Child and Adolescent Psychology, 31(4), 540-547. doi:10.1207/S15374424JCCP3104_12

Ryff, C. D. (1989). Happiness is everything, or is it? Explorations on the meaning of psychological well-being. Journal of Personality and Social Psychology, 57(6), 1069-1081. doi:10.1037/0022-3514.57.6.1069

Ryff, C. D., \& Singer, B. (2003). Ironies of the human condition: Well-being and health on the way to mortality. In L. G. Aspinwall \& U. M. Staudinger (Eds.), A psychology of human strengths: Fundamental questions and future directions for a positive psychology (pp. 271-287). Washington, DC: American Psychological Association.

Saarni, C. (2000). Emotional competence: A developmental perspective. In R. Bar-On \& J. D. A. Parker (Eds.), The handbook of emotional intelligence: Theory, development, assessment and application at home, school, and in the workplace (pp. 68-91). San Francisco, CA: Jossey-Bass.

Salovey, P., \& Mayer, J. D. (1990). Emotional intelligence. Imagination, Cognition and Personality, 9(3), 185-211. doi:10.2190/DUGG-P24E-52WK-6CDG

Swinkels, A., \& Giuliano, T. A. (1995). The measurement and conceptualization of mood awareness: Monitoring and labeling one's mood states. Personality and Social Psychology Bulletin, 21(9), 934-949. doi:10.1177/0146167295219008

Thompson, R. A. (1991). Emotional regulation and emotional development. Educational Psychology Review, 3(4), 269-307. doi:10.1007/BF01319934

Wong, C.-S., \& Law, K. S. (2002). The effects of leader and follower emotional intelligence on performance and attitude: An exploratory study. The Leadership Quarterly, 13(3), 243-274. doi:10.1016/S1048-9843(02)00099-1

\section{In Korean}

Ahn, H.-N., Lee, N.-B., \& Joo, H.-S. (2013). Validation of the cognitive emotion regulation questionnaire in a Korean population. Korean Journal of Counseling, 14(3), 17731794.

An, J., \& Yoo, S. (2016). The mediating effect of cognitive emotion regulation strategies in the relationship between acceptance action and psychological well-being of college students. Journal of Youth Welfare, 18(2), 173-197. doi:10.19034/ KAYW.2016.18.2.08

Chang, J. J., \& Kim, J. M. (2011). The effect of emotional awareness based expression training on emotional awareness, emotional expression, suppression of emotional expression and interpersonal relationship. The Korean
Journal of Counseling and Psychotherapy, 23(4), 861-884.

Choi, E.-S., \& Bang, H.-J. (2013). The emotional identification and expression abilities improvement program. The Korean Journal of Developmental Psychology, 26(1), 17-39.

Choi, H.-Y., Lee, D., \& Min, K.-W. (2008). Clusters by affect intensity, emotional attention, emotional clarity, and ambivalence over emotional expression and psychological adjustment. The Korean Journal of Social and Personality Psychology, 22(4), 59-73.

Choi, W.-K., \& Kim, J.-S. (2012). The relation between stress and suicide ideation among college students: The moderating and mediating effects of cognitive emotion regulation. Korean Journal of Counseling, 13(1), 255-272.

Han, M., Choi, I., Kim, B., Lee, H., Kim, K., \& Ryu, S. (2012). Happiness of Korean adolescence: Age-based comparison. Korean Journal of Youth Studies, 19(5), 217-235.

Hayes, A. F. (2015). Introduction to mediation, moderation, and conditional process analysis: A regression-based approach (1st ed., H. Lee, Trans.). Seoul: Shinyoungsa. (Original work published 2013)

Hong, S., \& Park, S. Y. (2017). Autonomy and relatedness satisfaction predicting psychological well-being of adolescents: Focusing on individualism-collectivism cultural values. Korean Journal of Child Studies, 38(2), 5-16. doi:10.5723/kjcs.2017.38.2.5

Jun, S.-M., \& Oh, I.-S. (2011). Relations between adolescents' emotion processing type and psychological well-being by gender. Korean Journal of Counseling, 12(5), 1737-1752.

Jung, S. (2018). The effects of stress on psychological well-being among college students: The mediating effects of emotional awareness. The Journal of Humanities and Social science, 9(4), 427-439. doi:10.22143/HSS21.9.4.32

Kim, H. W., \& Oh, I. (2016). Mediating effect of interpersonal problem between cognitive emotion regulation strategies and psychological well-being of adolescents. The Korea Journal of Youth Counseling, 24(1), 151-171.

Kim, J., \& Kwon, S. (2015). The influence of character strengths and personality disorders on well-being and depression. Clinical Psychology in Korea: Research and Practice, 1(1), 1-19.

Kim, M., \& Kwon, K. (2008). A study on the emotional clarity and the cognitive emotion regulation of resilient adolescents. The Korea Journal of Youth Counseling, 16(1), 15-32.

Kim, S., \& Min, K.-H. (2006). Personality, emotional characteristics, and subjective well-being of individuals who are overwhelmed with their emotions. Korean Journal of Social and Personality Psychology, 20(3), 45-66.

Kim, S.-H. (2004). A study on relationships among the stressful events, cognitive emotion regulation strategies and psychological well-being (Master's thesis). Retrieved from http://www.riss. 


\section{$\mathrm{kr} /$ link?id=T9560970}

Kim, S.-H. (2008). A study on relationships among the stressful events, cognitive emotion regulation strategies and psychological well-being. Journal of Student Guidance and Counseling, 26, 5-29.

Kim, Y. (2014). The relationship among type of emotional processing and cognitive emotional regulation, subjective well-being, positive affect and negative affect in college student. Korean Journal of Youth Studies, 21(5), 439-461.

Lee, J.-Y., \& Kwon, S.-M. (2006). Relationship between emotion regulation and psychopathology: Recent research trends and future research tasks. The Korean Journal of Counseling and Psychotherapy, 18(3), 461-493.

Lee, M. (2014). The effects of adolescents' perfectionism, parent and peer attachment on depression. Studies on Korean Youth, 25(4), 87-112. doi:10.14816/sky.2014.11.75.87

Lee, M.-J. (2013). The effects of perceived maternal attitudes and emotional clarity on psychological well-being of undergraduate students. Korean Journal of Counseling, 14(1), 17-35.

Lee, S.-J., \& Hyun, M.-H. (2008). The influence of emotional awareness and cognitive emotion regulation to mental health. The Korean Journal of Health Psychology, 13(4), 887905.

Lee, S.-J., \& Lee, H.-K. (1997). The research on the validation of the trait meta-mood scale: The domain exploration of the emotional intelligence. Korean Journal of Social and Personality Psychology, 11(1), 95-116.

Lim, J.-O. (2014). A study related to the emotional intelligence of counselors, counseling relationships, and counseling outcomes (Doctoral dissertation). Retrieved from http://www.riss.kr/ link?id=T13358899

Lim, J.-O., \& Chang, S.-S. (2003). A study on relationships among the emotional clarity, emotion regulation style, and psychological well-being. The Korean Journal of Counseling and Psychotherapy, 15(2), 259-275.

Nam, Y.-M., \& Park, C.-O. (2017). The effect of emotional clarity on posttraumatic growth among individuals with traumatic experience: The mediation effects of adaptive cognitive emotion regulation strategies. Korean Journal of Counseling, 18(3), 23-41.

Park, H., \& Chae, P. K. (2012). The mediating effects of emotion regulation strategies on the relationship between mindfulness and psychological well-being. Cognitive Behavior Therapy in Korea, 12(3), 259-274.

Park, J.-H., \& Sim, H.-S. (2007). Development of a psychological well-being inventory of adolescents. Asian Journal of
Education, 8(4), 111-135.

Park, M.-A., Kim, S.-K., \& Cheon, S.-M. (2013). A meta analysis on the factors of adolescent's psychological well being. Journal of Rehabilitation Psychology, 20(3), 627-652.

Shin, J. Y., Lee, Y. A., \& Lee, K.-H. (2005). The effects of life meaning and emotional regulation strategies on psychological well-being of Korean adolescents. The Korean Journal of Counseling and Psychotherapy, 17(4), 1035-1057.

Song, J.-W., \& Jo, H. (2018). The influence of daily stress on psychological well-being of adolescents: Mediating effects of cognitive emotion regulation strategies. Korean Journal of Youth Studies, 25(8), 103-129. doi:10.21509/ KJYS.2018.08.25.8.103

Yoo, A. J., Lee, J. S., \& Jung, H. S. (2006). Emotion regulation style and parent attachment: Effects on adolescents satisfaction with life. Korean Journal of Child Studies, 27(1), 167-181.

Yoo, S. (2014). Relationship between cognitive emotion regulation and psychological well-being of university students. Journal of Adolescent Welfare, 16(2), 183-202.

Yun, K.-H., \& Lee, S. (2016). The effects of temperament and parenting affective attitude, social supports on their subjective well-being of middle school students. Korea Association of Parent Counseling and Play Therapy, 7, 59-78.

\section{ORCID}

Taehee Kwak http://orcid.org/0000-0002-6611-9712

JungHa Lim https://orcid.org/0000-0002-0638-0687

Received October 21, 2018

Revision received January 3, 2019

Accepted January 30, 2019 